\title{
Optimization Of Fiber Glass Making Process For Electric Car Body Using Taguchi Method
}

\author{
Roymons Jimmy Dimu ${ }^{1}$, Antonius Pangalinan ${ }^{1}$, Oktovianus Dharma Rerung ${ }^{1}$ \\ \{roydimu@gmail.com, antoniuspangalinan74@gmail.com, dharmarerung@gmail.com\}
}

State Politeknik Negeri Kupang

\begin{abstract}
The purpose of this study to determine the optimum factor and level of the manufacturing process of composite fiber glass. This research will adopt the Design of Experiment (DOE) the Taguchi method with orthogonal L9 $\left(3^{4}\right)$, combination 4 factors 3 levels. The matrix used is the polyesters matrix and E-glass filler and the factors and level factors used in this study are fiber volume : $(35 \%, 40 \%, 45 \%)$, the composition of the mixture of matrix and talk: $(1: 1,2: 1,3: 1)$, fiber location: $\left(0^{\circ} / 90^{\circ},-45^{\circ} / 45^{\circ}\right.$, random), mixing time: ( 0.5 minutes, 1 minute, 1.5 minutes). On the results of the Taguchi method analysis optimum conditions for the process of making glass fiber composites against tensile stress are the location of the fiber $90^{\circ}$, resin mixture and filler $2: 1$, mixing time 1.5 minutes, fiber volume $45 \%$. The optimum conditions for the process of making glass fiber composites against the Impact Price are the location of the fiber $90^{\circ}$, mixing time 1 minute, fiber volume $45 \%$, resin mixture and filler 3:1.
\end{abstract}

Keywords: Optimization; Fiber Glass; Taguchi Method

\section{Introduction}

The development of the production of electric motorized vehicles is running fast today, as one of the efforts to solve the problem of the world energy crisis. Energy use is inversely proportional to energy availability. The availability of fossil energy, the exploitation of energy sources, has caused the world to experience an energy crisis. The biggest use of fossil energy is in the transportation sector. Along with these problems the development of electric motorized vehicles is developing rapidly. Studies concerning electric car body made from composites are also being developed to achieve a lightweight, flexible, economical, but strong and tough car body [1]. Composite is an alternative material that can be used to meet those needs. Composite material is a combination of reinforcement and matrix. The advantages of composite materials when compared to metals are high strength to weight ratio, stiffness, corrosion resistance and others. Therefore, today composite technology is experiencing very rapid progress that can be seen by the many studies concerning composite materials both from the matrix / binder, reinforcement / fiber and also additional material as a filler / filler composite itself [2]. The bond quality between the matrix and the filler is influenced by several variables such as volume friction and mixing time [2]. Factors in the process of making composites determine the mechanical properties of composites. Therefore, the problem formulation in this research is how to set factors in the process of making glass fiber composites to optimize mechanical properties. 
The purpose of this study was to determine how the relationship between the factors of the glass fiber manufacturing process with mechanical properties. And to find out the most dominant factors affecting mechanical properties in the process of making glass fiber composites, this study will adopt the Design of Experiment (DOE) with the Taguchi Method. This method was also chosen because it has a high level of effectiveness and a small number of experiments which saves time and money [3].

\section{Research Method}

As for some previous studies that became the first reference that is the effect of the orientation of the glass fiber on the impact strength on the body of the prototype electric car produced, the making of glass fiber composites by random arrangement using a mixture of reinforcing material and 1: 2.7 binding material produces the highest impact strength value of $557.33 \pm 38.68 \mathrm{kgm} / \mathrm{m}^{2}$ [1]. A second study on the optimization of the value of the tensile strength of composite manufacture uprs - cantula generated 3D With Taguchi method Optimal Value achieved Pull strength $26.61 \mathrm{MPa}$, at a combination of level factors, yarn count $\mathrm{Ne} 10.8$, yarn twist 500, woven 16 cards and 35\% resin concentration [4]. In the third study, Application of Taguchi Method to Reduce Disability in Paving Products from the application results can reduce paving disability by $3 \%$ / day [5]. The fourth study, the effect of woven angle and the suppression process on tensile stress on natural fiber laminate composite results in tensile strength values at woven angles of $0^{\circ} / 90^{\circ}$ greater than $45^{\circ} /-45^{\circ}$ [6]. And in fiveth study, optimization of mechanical properties of rotan skin fiber composite using taguchi method the optimum condition of impack strength is obtained in the composition of $40 \%$ rattan fiber with a length of $5 \mathrm{~cm}$ : $60 \%$ polyester, stirring time of 1 minute, and stirring speed of $100 \mathrm{rpm}$ [7].

Before conducting experiments, it is necessary to make a fishbone diagram to be able to determine the factors that are expected to affect the mechanical properties of glass fiber composites. These factors are divided into 4 categories: fiber volume, resin and filler mix, fiber location, mixing time.

Then from the fishbone diagram the experimental variables are determined namely:

1. Response variables: the mechanical properties of the composite fiber glass.

2. Independent variables / factors, consisting of:

- $\quad$ Fiber volume

- Mixture of resin and filler

- Location of fiber

- $\quad$ Mixing time

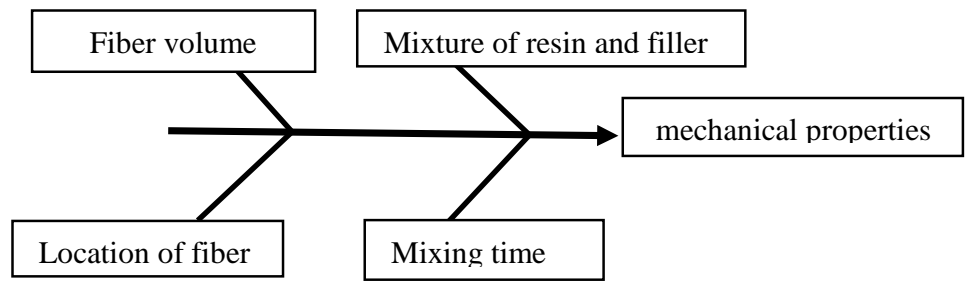

Figure 1. Fishbone diagrams influence factors on mechanical properties. 
Based on fishbone diagrams and literature studies in previous studies, the factors and levels of factors that might affect the mechanical properties of glass fiber composites are obtained in this study:

Table 1. Factors and factor levels.

\begin{tabular}{|c|l|c|c|c|}
\hline \multirow{2}{*}{ Code } & \multicolumn{2}{|c|}{ Factors } & \multicolumn{3}{|c|}{ Levels } \\
\cline { 3 - 5 } & & 1 & 2 & 3 \\
\hline A & Fiber volume & $35 \%$ & $40 \%$ & $45 \%$ \\
\hline B & Mixture of resin and filler & $1: 1$ & $2: 1$ & $3: 1$ \\
\hline C & Location of fiber & $0^{0} / 90^{0}$ & $-45^{0} / 45^{0}$ & random \\
\hline D & Mixing time & 0.5 minute & 1 minute & 1,5 minute \\
\hline
\end{tabular}

Orthogonal array is a balance matrix that shows the assignment of experimental factors. The steps that must be taken in determining the orthogonal array are as follows:

a. Count the number of free degrees

Calculation of degrees of freedom is done to calculate the minimum number of experiments that must be carried out to investigate the observed factors. The total degrees of freedom are the sum of the degrees of freedom from each factor. The results of calculating the degree of controlled factors are described in table 2 below:

Table 2. Controllable degrees of freedom factor

\begin{tabular}{ccc}
\hline Factor & $\begin{array}{c}\text { Degree of } \\
\text { freedom }\end{array}$ & Total \\
\hline A,B,C,D 4 X (3-1) & 8 \\
Total degree of freedom & 8 \\
\hline
\end{tabular}

b. Choose an orthogonal array that has a free degree of at least 8 experiments.

Based on table 2. the total degrees of freedom required for a controlled factor is 8 , so the orthogonal array of controllable factors that is appropriate is L9 $\left(3^{4}\right)$ [8] [9].

Table 3. Orthogonal array L9 $\left(3^{4}\right)$ experiment parameters

\begin{tabular}{|c|c|c|c|c|c|c|c|}
\hline No & A & B & C & D & R1 & R2 & R3 \\
\hline 1 & 1 & 1 & 1 & 1 & & & \\
\hline 2 & 1 & 2 & 2 & 2 & & & \\
\hline 3 & 1 & 3 & 3 & 3 & & & \\
\hline 4 & 2 & 1 & 2 & 3 & & & \\
\hline 5 & 2 & 2 & 3 & 1 & & & \\
\hline 6 & 2 & 3 & 1 & 2 & & & \\
\hline 7 & 3 & 1 & 3 & 2 & & & \\
\hline 8 & 3 & 2 & 1 & 3 & & & \\
\hline 9 & 3 & 3 & 2 & 1 & & & \\
\hline
\end{tabular}


In this experiment used 4 factors with a 3 level design, from the number of levels and factors that can be determined the number of rows for orthogonal matrix is 9 , which shows the number of experiments as many as 9 runs. This run was replicated 3 times so that the total number of experiments was 27 experiments.

The steps of the experiment are as follows :

$>$ Preparation of tools and materials:

1. Materials

a. Fiber Reinforcement

The reinforcement fibers are selected from Woven Roving type E-glass fibers which were previously woven in the direction of the fibers later rearranged according to the Taguchi experimental design..

b. Matrix

Matrix used Polyester resin with catalyst additives which acts as a resin and filler hardener as well as a wax that serves to facilitate the release of specimens from the mold.

2. Tools

a. Wood molds according to ASTM D 638 type III standard and ASTM D 5942 Impack with glass pressure pad [10].

b. Paperclip To staple the print with a glass backing.

c. Cutter and Scissors for cutting fiber.

d. Measuring cup to measure the mixture of resin and filler material.

e. Digital scales to measure fiber weight and filler.

f. Ruler / calipers.

g. Saws, sandpaper for finishing.

h. Rubber gloves.

i. A brush to press the fibers to blend them perfectly.

j. Stop watch to measure mixing time.

Making tensile test specimens with dimensions according to ASTM D 638 standard (27 samples) and ASTM D 5942 impack testing (27 samples) according to a combination of composite manufacturing processes (in table 3 Orthogonal Array L9 $\left(3^{4}\right)$ experimental parameters).

The process of making composites is as follows:

1) Calculate the total mold volume of tensile and impack test specimens.

2) Cut the fibers according to the size of the mold and rearrange the fibers (previously the form of woven) so that it is easy to put on the mold and weigh the fiber according to the volume of the Taguchi experiment. The wood mold is cleaned and the surface is then applied with wax / lubricant (PVA) to prevent the specimen from sticking to the mold so that it is easy to remove.

3) Mix the resin and filler according to the ratio of the measuring cup according to the taguchi experiment combination, then mix until blended.

4) Pour the catalyst into the mixture as much as $2 \mathrm{cc}$ and mix it during the mixing time of the Taguchi experiment.

5) The mixture is then poured into a mold, followed by the insertion of fibers into the mold according to the location and volume of the Taguchi experiment combination followed by an emphasis so that the fibers are evenly mixed.

6) Thoroughly press the mold using glass and then clamp it with a paper clips.

7) Leave the specimen in the mold 3-4 hours at room temperature.

8) Open the mold by removing the clamp and removing the specimen using a cutter. 
9) Allow the specimen to dry completely and then finish according to the test size.

10) once the manufacturing process will produce 3 test samples.

11) Retouching the process of making samples according to a combination of factors and taguchi experiment levels, until 27 pull test samples and 27 impact test samples are formed.

Processing analysis of mean data using the Taguchi method.

$>$ Got an optimum combination of factors and the level of the manufacturing process of composite.

\section{Results and Discussion}

Table 4. Tensile test data

\begin{tabular}{llllll}
\hline No & $\begin{array}{c}\text { Fiber } \\
\text { volume }\end{array}$ & $\begin{array}{c}\text { Mixture of } \\
\text { resin and } \\
\text { filler }\end{array}$ & $\begin{array}{c}\text { Location of } \\
\text { fiber }\end{array}$ & Mixing time & $\begin{array}{c}\text { tensile stress } \\
\left(\mathrm{N} / \mathbf{m m}^{2}\right)\end{array}$ \\
\hline 1 & $35 \%$ & $1: 1$ & $90^{\circ}$ & 0,5 minute & $\mathbf{2 5 , 5 1 7}$ \\
2 & $35 \%$ & $2: 1$ & $45^{\circ}$ & 1 minute & $\mathbf{6 , 3 0 5}$ \\
3 & $35 \%$ & $3: 1$ & acak & 1,5 minute & $\mathbf{2 8 , 5 7 1}$ \\
4 & $40 \%$ & $1: 1$ & $4^{\circ}$ & 1,5 minute & 10,823 \\
5 & $40 \%$ & $2: 1$ & acak & 0,5 minute & $\mathbf{2 7 , 2 0 8}$ \\
6 & $40 \%$ & $3: 1$ & $90^{\circ}$ & 1 minute & $\mathbf{5 1 , 4 8 6}$ \\
7 & $45 \%$ & $1: 1$ & acak & 1 minute & 16,162 \\
8 & $45 \%$ & $2: 1$ & $90^{\circ}$ & 1,5 minute & $\mathbf{9 0 , 7 6 6}$ \\
9 & $45 \%$ & $3: 1$ & $45^{\circ}$ & 0,5 minute & $\mathbf{8 , 2 0 2}$ \\
\hline
\end{tabular}

In table 4 the tensile test results show that the highest tensile stress is $90.766 \mathrm{~N} / \mathrm{mm}^{2}$ with a design of $45 \%$ fiber volume experiment, 2 : 1 resin and filler mix ratio, $90^{\circ}$ fiber location and 1.5 minute mixing time.

Based on the analysis of the Taguchi method with minitab 19 software can be ranked based on the factors and levels of the process of making glass fiber composites that affect the tensile stress. Ranking results can be seen in the table below:

Table 5. Ranking factors and levels with the Taguchi method for tensile stress.

\begin{tabular}{lrrrr} 
Level & Fiber volume & $\begin{array}{r}\text { Mixture of resin } \\
\text { and filler }\end{array}$ & $\begin{array}{r}\text { Location of } \\
\text { fiber }\end{array}$ & Mixing time \\
\hline 1 & 20,131 & 17,501 & 55,923 & 20,309 \\
2 & 29,839 & 41,426 & 8,443 & 24,651 \\
3 & 38,377 & 29,420 & 23,980 & 43,387 \\
Delta & 18,246 & 23,926 & 47,480 & 23,078 \\
Rank & 4 & 2 & 1 & 3
\end{tabular}

Based on the results of ranking using minitab 19 software on the response table the average value seen factors that most influence the tensile stress of the first location of the fiber, the second mixture of resin and filler, the third mixing time, the fourth volume of fiber. 


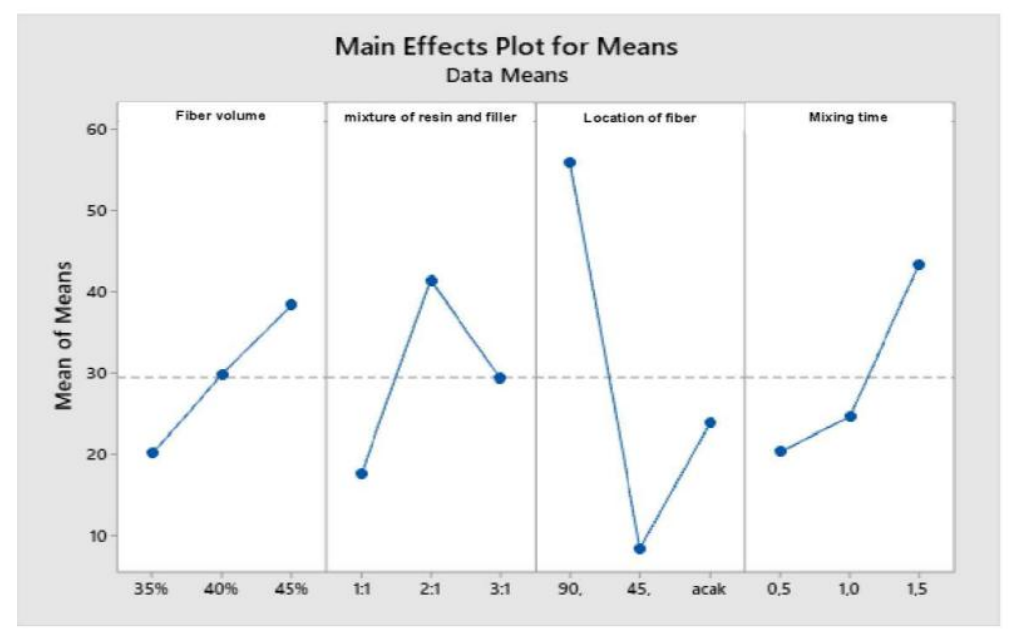

Figure 2. The relationship between controlled factors with tensile stress

Based on the graph response for the average value, it is known that the optimum condition of the composite manufacturing process from the optimum condition graph plot is $90 \mathrm{o}$ fiber location, resin mixture and 2: 1 filler, 1.5 minute mixing time, $45 \%$ fiber volume.

Table 6. Impact testing data

\begin{tabular}{|c|c|c|c|c|c|}
\hline NO & $\begin{array}{c}\text { Fiber } \\
\text { volume }\end{array}$ & $\begin{array}{c}\text { Mixture of resin } \\
\text { and filler }\end{array}$ & $\begin{array}{c}\text { Location of } \\
\text { fiber }\end{array}$ & Mixing time & $\begin{array}{c}\text { Impact Price } \\
\left(\mathbf{J} / \mathbf{m m}^{2}\right)\end{array}$ \\
\hline 1 & $35 \%$ & $1: 1$ & $90^{\circ}$ & 0,5 minute & 0,0409 \\
\hline 2 & $35 \%$ & $2: 1$ & $45^{\circ}$ & 1 minute & 0,0026 \\
\hline 3 & $35 \%$ & $3: 1$ & acak & 1,5 minute & 0,0076 \\
\hline 4 & $40 \%$ & 1:1 & $45^{\circ}$ & 1,5 minute & 0,0024 \\
\hline 5 & $40 \%$ & $2: 1$ & acak & 0,5 minute & 0,0055 \\
\hline 6 & $40 \%$ & $3: 1$ & $90^{\circ}$ & 1 minute & 0,1067 \\
\hline 7 & $45 \%$ & 1:1 & acak & 1 minute & 0,0282 \\
\hline 8 & $45 \%$ & $2: 1$ & $90^{\circ}$ & 1,5 minute & 0,0975 \\
\hline 9 & $45 \%$ & $3: 1$ & $45^{\circ}$ & 0,5 minute & 0,0055 \\
\hline
\end{tabular}

In table 6. the Impact raining results show that the highest Impact price is $0.1067 \mathrm{~J} / \mathrm{mm} 2$ with a design of experiment of $40 \%$ fiber volume, resin mixture and filler ratio of 3: 1, location of fiber 900 and mixing time of 1 minute..

Based on the analysis of the Taguchi method with minitab 19 software can be ranked based on the factors and levels of the process of making glass fiber composites that affect the impact price. Ranking results can be seen in the table below : 
Tabel 7. Ranking factors and levels using the Taguchi method for impact prices

\begin{tabular}{|l|r|r|r|r|}
\hline Level & Fiber volume & $\begin{array}{r}\text { Mixture of resin } \\
\text { and filler }\end{array}$ & $\begin{array}{r}\text { Location of } \\
\text { fiber }\end{array}$ & Mixing time \\
\hline 1 & 0,017033 & 0,023833 & 0,081700 & 0,017300 \\
\hline 2 & 0,038200 & 0,035200 & 0,003500 & 0,045833 \\
\hline 3 & 0,043733 & 0,039933 & 0,013767 & 0,035833 \\
\hline Delta & 0,026700 & 0,016100 & 0,078200 & 0,028533 \\
\hline Rank & 3 & 4 & 1 & 2 \\
\hline
\end{tabular}

Based on the results of ranking using minitab 19 software on the response table the average value seen the factors that most influence the price of the Impact is the first location of the fiber, the second time of mixing, the third volume of fiber, the fourth mixture of resin and filler.

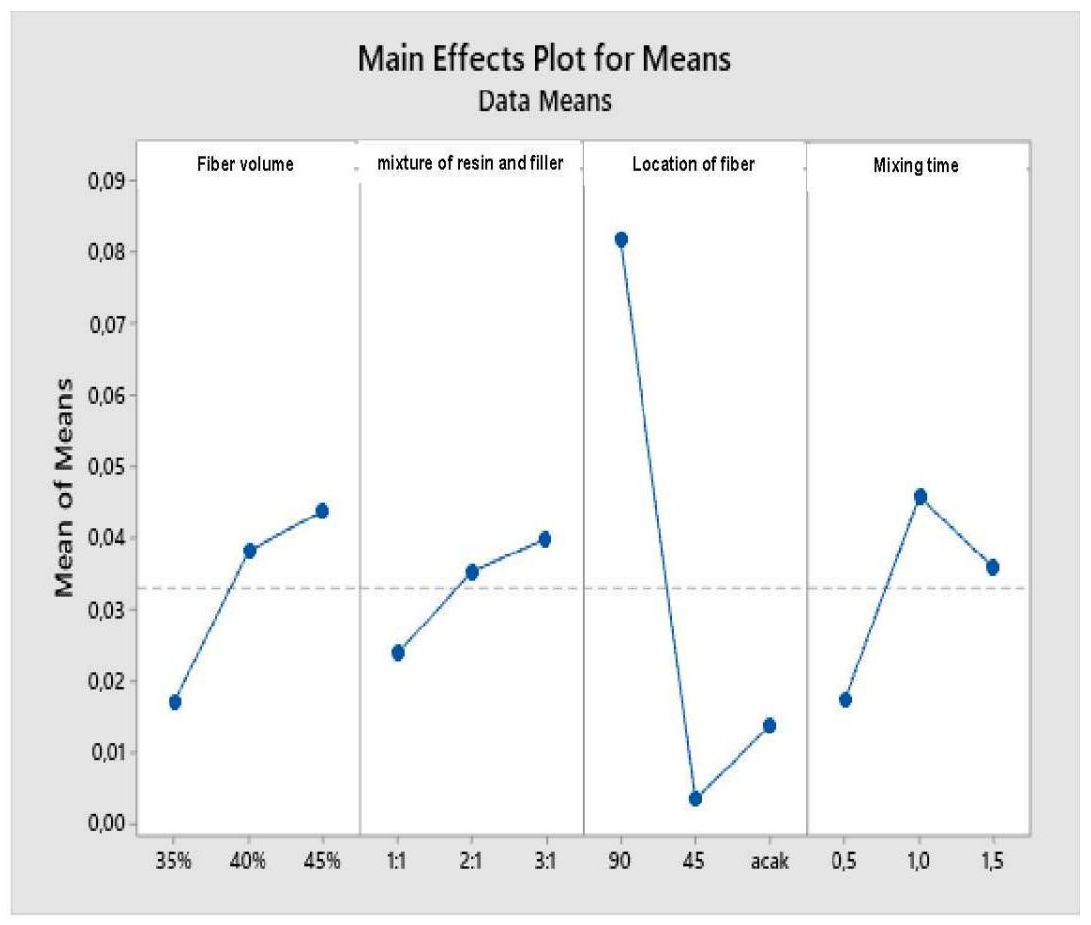

Figure 8. The relationship between controlled factors on impact prices

Based on the graph response for the average value of the Impact price, it is known that the optimum conditions of the composite manufacturing process from the optimum condition graph plot are $90^{\circ}$ fiber location, 1 minute mixing time, $45 \%$ fiber volume, resin mixture and 3: 1 filler. 


\section{Conclusion}

The optimum conditions for the process of making fiberglass composites against tensile stress are the location of $90^{\circ}$ fibers, resin mixture and 2: 1 filler, mixing time 1.5 minutes, fiber volume $45 \%$.

The optimum conditions for the process of making glass fiber composites on the impact price are $90^{\circ}$ fiber location, 1 minute mixing time, $45 \%$ fiber volume, resin mixture and 3: 1 filler.

$90^{\circ}$ fiber layout is a factor and the level of the most dominant influence on the tensile stress and Price Impact.

\section{References}

[1] P. E.W, "The Effect of Glass Fiber Orientation on the Impact Strength on the Prototype Body of an Electric Car," J. Sci. Technol. Adhi Tama Inst. Technol. Surabaya, vol. 21, no. 1, pp. 35-42, 2017.

[2] Ristekdikti, White Paper on Advanced Material Technology. 2010.

[3] O. Novareza, "Application of Taguchi Experiment for the Composition Optimization of Raw Material in Making of Terrazo Chair," J. Enviromental Eng. Sustain. Technol., vol. 4, no. 2, pp. 103-110, 2017.

[4] W. L, "Optimizing Value Tensile Strength On Making Composite Uprs - Cantula 3d With Taguchi Method," J. Eng. ATW, Dep. Text. Eng. Acad. Technol. Resid. Surakarta., vol. 11, pp. 16-25, 2014.

[5] D. Anggraini, S. K. Dewi, and T. E. Saputro, "Application of Taguchi Method to Reduce Disability in Paving Products," J. Ind. Eng., vol. 16, no. 1, pp. 1-9, 2017.

[6] K. Anam, A. Purnowidodo, and S. A. Setyabudi, "Effect of Angle Woven And Pull Voltage Process Against Emphasis On Natural Fiber Composite Laminate," J. Mech. Eng., vol. 9, no. 3, pp. 155-162, 2018.

[7] A. B, "Optimization of Mechanical Properties of Composite Fiber Leather Rattan And Polyester With Taguchi Methods,” J. Chem. Inf. Model., vol. 53, no. 9, pp. 1689-1699, 2019.

[8] R. J. Dimu, D. Widhiyanuriyawan, and S. Sugiono, "Optimization of Medium Carbon Steel Hardening With Banana Tree Fluid Using the Taguchi Method," J. Mech. Eng., vol. 5, no. 2, p. pp.135-140, 2014.

[9] P. Sidi and Muhammad Thoriq Wahyudi, "Application of Taguchi Method to Know Roundness Optimization in CNC Lathe Process," J. Mech. Eng. Dep. Sh. Eng. Surabaya State Shipbuild. Polytech., vol. 4, no. 2, pp. 101-108, 2013.

[10] J. Johanis Abanat, A. Purnowidodo, and Y. Irawan, "Effect of fiber volume fraction (Corypha Utan Lamarck) on Mechanical Properties of Epoxy Patterned Composites," J. Mech. Eng., vol. 3, no. 2 , pp. 352-361, 2012. 